\title{
The history of COPD
}

\author{
Thomas L Petty \\ University of Colorado Medical \\ Center, Denver, CO, USA; \\ Rush-Presbyterian-St Luke's Medical \\ Center, Chicago, II, USA
}

\begin{abstract}
The evolution of knowledge concerning COPD and its components - emphysema, chronic bronchitis, and asthmatic bronchitis - covers 200 years. The stethoscope and spirometer became important early tools in diagnosis and assessment. Spirometry remains the most effective means of identification and assessment of the course of COPD and responses to therapy, and is grossly underused for this purpose. Knowledge of the pathogenesis, course and prognosis, and new approaches to therapy have dramatically improved our understanding of this important clinical entity. Smoking cessation improves the early course of disease. Long-term oxygen improves the length and quality of life in selected patients with hypoxemia. Surgery benefits a select few. Today, COPD is a steadily growing global healthcare problem, with increasing morbidity and mortality. Early identification and prevention, and treatment of emerging stages of disease through smoking cessation and a growing number of bronchoactive drugs promises to change the outcome.
\end{abstract}

Keywords: COPD, emphysema, pathogenesis, natural history, treatment

\section{Introduction}

Chronic obstructive pulmonary disease is finally gaining the attention needed to begin to solve this common problem. It is defined as chronic airflow obstruction that is progressive and only partly reversible (Pauwels et al 2001; Global Initiative for Chronic Obstructive Lung Disease 2004). COPD includes chronic bronchitis, emphysema, and chronic asthmatic bronchitis (defined further below). Today, COPD is the fourth most common cause of death in the USA, and is the only disease state that is rising in morbidity and mortality amongst the top five killers. It resulted in a $\$ 32.1$ billion loss to the USA economy in direct and indirect costs in 2003, and by 2020 is expected to become the third most common cause of death (NHLBI Data Fact Sheet 2003). Approximately 16 million adult Americans have COPD. Probably an equal number have asymptomatic or even symptomatic disease but are not diagnosed or treated (Mannino et al 2000). Interest in COPD is a recent development and few know the origins of this interesting disease spectrum. This review offers a glimpse into the rich history in the development of our present understanding of COPD.

\section{Early historical landmarks}

Some of the earliest references to the description of emphysema include: Bonet's description of "voluminous lungs" in 1679 (Bonet 1679); Morgagni's (1769) description of 19 cases in which the lungs were "turgid", particularly from air; and Baille's illustrations of the emphysematous lung, thought to be that of Samuel Johnson (Baillie 1789; Bishop 1959).

The beginnings of our clinical understanding of the chronic bronchitis component of COPD can be traced to Badham (1814), who used the word catarrh to refer to the chronic cough and mucus hypersecretion that are cardinal symptoms. He described bronchiolitis and chronic bronchitis as disabling disorders (Badham 1814). 
The emphysema component of disease was beautifully described by Laënnec (1821) in his Treatise of diseases of the chest. Laënnec, a clinician, pathologist, and inventor of the stethoscope, did careful dissections of patients that he had studied during life. He recognized that emphysema lungs were hyperinflated and did not empty well (Laënnec 1821).

In his A treatise on the diseases of the chest and on mediate auscultation (1837, $\mathrm{p}$ 81) Laënnec wrote on emphysema:

The disease which I designate by this title is very little known and has not hitherto been correctly described by any author. I for a long time thought it very uncommon, because I had observed only a few cases of it: but since I have made use of the stethoscope, I have verified its existence as well on the living as the dead subject, and am led to consider it as by no means infrequent. I consider many cases of asthma, usually deemed nervous, as depending on this cause. The chief reason of this affection having been so completely overlooked is, that it is in some sort merely the exaggeration of the natural condition of the viscus.

In this era, smoking was rare, but it is a fact that emphysema may occur in non-smokers, particularly with a familial predisposition or from environmental-provoking factors. Laënnec continued:

In opening the chest, it is not unusual to find that the lungs do not collapse, but they fill up the cavity completely on each side of the heart. When experienced, this will appear full of air ... . The bronchus of the trachea are often at the same time a good deal filled with mucous fluid (Laënnec 1821, p 89).

Thus Laënnec had described a combination of emphysema and chronic bronchitis.

John Hutchinson invented the spirometer in 1846 (Hutchinson 1846). The spirometer is key to the diagnosis and management of COPD, yet its use is still poorly applied to the diagnosis and management of COPD in most locations in the world today. Hutchinson's instrument only measured vital capacity. It took another 100 years for Tiffeneau to add the concept of timed vital capacity as a measure of airflow, for spirometry to become complete as a diagnostic instrument (Tiffeneau and Pinelli 1947).

Osler's Principles and practices of medicine (1916) says little about emphysema. Osler believed emphysema was caused by excessive pressure in the alveoli (Osler 1916), and reference to the spirometer cannot be found in this classic text. In 1912, another author did not mention spirometry, but shows a nice picture of the sphygmomanometer, invented by Rico Rossi in 1896, and excellent quality EKG strips are shown (Bovard 1912). This occured 50 years after Hutchinson's invention. A textbook of Disease in the chest in 1918 makes only brief mention of spirometry with no illustrations (Norris and Landis 1918).

Gaensler introduced the concept of the air velocity index based on Tiffeneau's work and later the forced vital capacity, which is the foundation of the $\mathrm{FEV}_{1}$ and $\mathrm{FEV}_{1} / \mathrm{FVC}$ percent (Gaensler 1950, 1951).

In 1944, one of the great teachers of emphysema, Ronald Christie, suggested that "The diagnosis should be considered certain when dyspnea on exertion, of insidious onset, not due to bronchospasm, or left ventricular failure, appears in a patient who has some physical signs of emphysema together with chronic bronchitis and asthma" (Christie 1944, p 145). It is clear from this statement that Christie recognized the individual components of COPD and relied on the history and physical examination for his diagnosis. Oswald described the clinical features of 1000 cases of chronic bronchitis in 1953 (Oswald et al 1953).

Barach and Bickerman (1956) edited the first comprehensive text book, Pulmonary emphysema, which nicely describes the treatment of the era. These two physicians were early champions of treatment for emphysema. Contributors to this book included Dayman, the first to recognize the spirometric and flow volume patterns indicative of dynamic expiratory airway collapse in emphysema; Dickerson Richards, Nobel Laureate, who wrote on the pulmonary circulation and cor pulmonale; Reuben Cherniack, who described respiratory acidosis and has made major contributions to our understanding of the diagnosis and treatment of emphysema for over half a century; and Menelee and Callaway, who described pulmonary function tests in emphysema patients. In all, 17 leading clinicians and clinical scientists contributed to this classic volume of the 1950s.

The first edition of Hinshaw and Garland (1956) (now Murray and Nadel) Textbook of respiratory medicine shows a nice picture of a Collins 13.5 liter recording spirometer, and shows capacity spirograms that demonstrate airflow limitation in emphysema.

\section{Definitions}

Two landmark meetings: The CIBA Guest Symposium in 1959 (Ciba Guest Symposium 1959; Donald 1971) and 
the American Thoracic Society Committee on Diagnostic Standards in 1962 defined the components of COPD, which are the foundation for our definitions today (Committee on Diagnostic Standards for Nontuberculous Respiratory Diseases 1962). The American Thoracic Society (ATS) defined chronic bronchitis in clinical terms including chronic cough lasting at least three months for at least two years. By contrast, the ATS defined emphysema in anatomic terms of enlarged alveolar spaces and loss of alveolar walls. Neither definition used any physiologic criteria. Asthma was described as a state of airway hyperresponsiveness to a variety of stimuli. Asthmatic bronchitis was considered an overlapping condition (Committee on Diagnostic Standards for Nontuberculous Respiratory Diseases 1962). (The author had the privilege of attending the deliberations of the ATS committee as a Resident in Medicine in 1962 in Memphis Tennessee during the time of the annual VA-Armed Forces Annual Conference on the Treatment of Tuberculosis.) Many other attempts to define COPD have not improved on these basic definitions, except that COPD is now defined in functional terms.

Other acronyms that predated the COPD designation were chronic obstructive bronchopulmonary disease, chronic airflow obstruction, chronic obstructive lung disease, nonspecific chronic pulmonary disease, and diffuse obstructive pulmonary syndrome. William Briscoe is believed to be the first person to use the term COPD in discussion at the 9th Aspen Emphysema Conference. This term became established and today we refer to COPD as the designation of this growing health problem (Briscoe and Nash 1965).

\section{Pathology}

In the past 50 years, the pathology of emphysema and other components of COPD have filled textbooks (Reid 1967; Heard 1969; Thurlbeck 1976). Loss of alveolar walls (emphysema), mucous gland hyperplasia (Reid index) in large conducting airways (Reid 1960), and bronchiolitis with fibrosis have been extensively documented and illustrated. Thurlbeck's book (1976) cites Jethro Gough and his first use of whole lung thin sections to illustrate the various types of emphysema (Gough 1952; Thurlbeck 1976).

The Dutch hypothesis and British hypothesis in pathogenesis were early basic concepts. The Dutch hypothesis presented the concept of genetically determined bronchial hyperreactivity in COPD (Orie and Sluiter 1960). The British hypothesis proposed that repeated chest infections and air pollution contributed to the pathogenesis of chronic bronchitis (Stuart-Harris et al 1953; Scadding 1959). Both hypotheses are probably correct, and both bronchial hyperreactivity and chest infections plus irritant exposure are important in pathogenesis.

\section{Experimental emphysema}

Many disease models have yielded clues to cause, pathophysiology, clinical manifestations, and therapeutic targets. Early attempts to produce experimental emphysema used obstructive devices placed in the major airways or trachea to attempt to reproduce hyperinflation. The author spent a research summer employing the use of a venturi device (that had greater expiratory than inspiratory resistance) placed in the trachea of dogs. This study did not produce hyperinflation or emphysema. In fact the dogs developed reduced functional residual capacity with the tracheal obstruction, a fact of tracheal obstruction that was not known by this naïve student investigator. A presentation on experimental emphysema at the First Aspen Emphysema Conference in 1958 documents this work and that of earlier investigators (Eiseman et al 1959).

The first credible production of emphysema was by Gross in 1964, who instilled pancreatic extracts (papain) into the airways of guinea pigs to cause destruction of alveoli and hyperinflation (Gross et al 1964). This was somewhat of a fortuitous discovery, since he was not trying to produce emphysema, but was hoping to determine the effect of papain on the fibrosis associated with experimental silicosis that he was studying. Gross's work produced emphysema, due to proteolytic damage of elastin and thus was the forerunner of the protease - antiprotease therapy of the pathogenesis, as described by Laurel and Erickson (1963) in Sweden with alpha-one-antitrypsin deficiency and emphysema. Other investigations also used elastases to produce experimental emphysema (Snider and Sherter 1977). Many genetic, infectious, and immunologic models in small animals followed and continue to be investigated at the present time. A recent model employing methylprednisolone to produce emphysema in rats induces matrix metalloproteinase and can be prevented by a metal proteinase inhibitor (Choe et al 2003). The concept that emphysema is an autoimmune vascular disease has been offered as one pathway in pathogenesis (Voelkel and TarasevicieneStewart 2005). Studies in experimental emphysema, though possibly species specific, are useful in suggesting new therapeutic targets. 


\section{The Aspen emphysema conferences}

The growing problem of emphysema and related disorders was the stimulus for a planned series of emphysema conferences held annually in Aspen, Colorado, beginning in 1958 (Mitchell 1959). Roger S Mitchell and his colleagues, Giles F Filley, and John R "Jack" Durrance, were the driving force that launched these landmark conferences. Financial support came from the Department of Medicine of the University of Colorado pulmonary division and local and national tuberculosis associations. The major topics of the first conference included the state-of-the-art understanding of anatomy, pathology, physiology, experimental studies, natural history, unusual forms, and allergy in relation to emphysema. JH McLean's pioneering work on bronchiolitis was and remains a highlight. Liebow described vascular injury including capillary loss in emphysema, and Loosli described loss of elastic fibers. Pierce discussed lung elastin and collagen, and Brantigan's lung volume reduction surgery was discussed as an innovative method of treating a small number of selected patients with advanced emphysema. Subsequent conferences discussed certain collateral subjects including asthma, the environment, and the lung and pulmonary circulation.

The conferences were intended to conclude after the 1964 meeting. However, the author, now on the junior faculty of the pulmonary division, and his colleagues had a burning desire to have one "last" conference on the treatment of COPD. Somewhat magically, the Chronic Respiratory Disease Branch of the Public Health Service generously supported the 8th Aspen Emphysema Conference. It presented new concepts in the management of acute respiratory failure, home care and rehabilitation, pharmacologic agents in current use, and the new concept of ambulatory oxygen in the treatment of advanced COPD. Surgical resection was again discussed by Brantigan, but now with caution because of high perioperative mortality.

This conference may have been the "tipping point" in the establishment of comprehensive treatment for COPD (Petty 1967). Because of the success of the 8th conference, the 9 th, 10 th, and 11th conferences were held annually at the same venue. These three conferences dealt with the mushrooming advances in research in COPD during that era. At the 9th conference Ben Burrows and Charles Fletcher presented their concept of "The bronchial and emphysematous types of chronic obstructive lung disease in London and Chicago", pointing out that the same disease spectrum was found on both sides of the Atlantic. This work was also published elsewhere (Burrows et al 1966). Fletcher gave his initial findings on "Prognosis in chronic bronchitis".

Subsequent conferences, namely the 12th, 22nd, 26th, and 44th conferences, have documented great progress in our understanding of all aspects of COPD and its treatment. The 48th was the most recent Thomas L Petty Aspen Lung Conference (its present name) to discuss COPD and related disorders, and began with a clinical theme emphasizing the different COPD phenotypes.

\section{Clinical-pathological correlations}

Roger S Mitchell and colleagues began a series of studies of the pathology of alveolar and airways damage in patients, participating in an early emphysema registry, who later died and had autopsies at the University of Colorado Medical Center. The focus was mostly on mucous gland hyperplasia and inflammation of large conducting airways and loss of alveolar walls (Mitchell et al 1966, 1968). The lesion of bronchiolitis (small airways) inflammation was also described by Mitchell et al (1976) in early reports.

\section{Structure/structure-function relations in COPD}

Also using an artificial thorax to ventilate fresh post-mortem lungs, the Denver Group began a series of systematic studies that were designed to evaluate structure/function relationships and the major lesions associated with COPD, loss of alveolar walls (emphysema), and mucous gland hyperplasia (chronic bronchitis) (Petty et al 1965). By ventilating a whole fresh excised human lung that had been obtained at autopsy, and occasionally was available at the time of donation of organs for transplantation, it was possible to study lung mechanics both from lungs in subjects with no clinical lung disease and in patients with various stages of COPD. The investigators could measure many physiologic indices, including $\mathrm{FEV}_{1}, \mathrm{FVC}$, maximum mid-expiratory flow, residual volume, and nitrogen washout tests, to study the physiologic expression of lesions of the small airways (Petty et al 1980, 1984, 1987). The measurement of the post-mortem $\mathrm{FEV}_{1}$ bore a close correlation with the $\mathrm{FEV}_{1}$ measured during life in the majority of patients ( $r=0.891)$, adjusted for both lungs (Petty et al 1965). Progressive grades of emphysema were associated with reductions in $\mathrm{FEV}_{1}$. The lesion of mucous gland hyperplasia (ie, the Reid index; Reid 1960) did not have a close correlation with airflow measurements. 
Dynamic airway collapse of the central airways was related to reductions in $\mathrm{FEV}_{1}$.

Accurate smoking histories were available in another series of 154 autopsied patients. Lesions of mucous gland hyperplasia and emphysema were found in nearly $50 \%$ of the smokers. Eight non-smokers also had these lesions (Petty et al 1967). Whether or not these patients had other risk factors for the development of the pathologic lesions associated with COPD is not known. This study was performed before the era of understanding the contributions of small airway pathology to airflow obstruction.

The landmark study by Hogg et al (1968) ushered in the era of small airways disease. To learn whether or not the nitrogen washout test would identify the lesions of small airways disease, the Denver Group performed additional studies on this and other tests that purported to identify early lesions in patients with COPD with emphysema and on the pathology of small airways (Petty et al 1980, 1984, 1987). Cosio et al (1978) provided his grading photomicrographs of mild, moderate, and severe inflammation and mild, moderate, and severe fibrosis of small airways. Emphysema was found to relate to a reduction in elastic recoil and in the

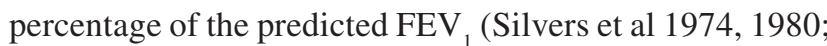
Petty et al 1984). Elastic recoil was inversely proportional to the closing capacity and the slope of phase III disease (Petty et al 1980). In addition, the maximum expiratory flow volume was not related to emphysema (Petty 1984). Fairly good correlations were found among the $\mathrm{FEV}_{1}$, FVC, and static lung recoil at $70 \%$ of inflation (Petty et al 1984). Increased lung size (TLC and FR) were related to loss of elastic recoils, but not to airflow obstruction (Petty et al 1987).

Numerous key studies initiated by the Montreal group (Cosio, Saetta, Angine, and others) have shown that reduced alveolar attachments, elastic recoil, and alveolar fenestrae are all interrelated and associated with smoking. Reduced elastic recoil is a major factor in the development of airflow limitation (Saetta, Shiner, et al 1985; Cosio et al 1986; Saetta 2001).

During the course of these studies, several unusual patients with COPD were encountered, including a 29-year-old man who died of end-stage emphysema and a 19-year-old man who had severe pulmonary hypertension, emphysema, and marked narrowing of the conducting airways of the lungs. The Denver studies also identified the lesion of duct ectasia (ie, an unwinding of alveolar ducts due to loss of elastic recoil) in nonsymptomatic aged individuals (Ryan et al 1965).

\section{The natural history of COPD}

Charles Fletcher devoted his life to the study of the natural history of COPD (Fletcher et al 1976). He recognized the risks of smoking and the accelerated rate of decline in $\mathrm{FEV}_{1}$ in susceptible smokers on the pathway to disabling symptoms (Fletcher et al 1976). He and his colleagues recognized that stopping smoking would retard the rate of $\mathrm{FEV}_{1}$ decline to that approaching the rates of reduction in age-related non-smokers (Peto et al 1983). This established the scientific foundation for smoking cessation in every stage of disease (see Lung Health Study) (Anthonisen et al 1994, 2005).

Burrows and Earle described the course and prognosis of 200 patients with COPD in his classic study in Chicago (Burrows and Earle 1969). Later, when observing similar patients in his lifelong study of prognosis of emphysema in a large population in Tucson, Arizona, he recognized that patients with a low $\mathrm{FEV}_{1} / \mathrm{FVC}$ percentage predicted the onset of rapid decline in $\mathrm{FEV}_{1}$ over time. Patients with the most rapid rate of decline had the worst prognosis. He termed this phenomenon as "The Horse Racing Effect" (Burrows et al 1987). The discovery also established the importance of early identification and intervention (see section titled The NLHEP and GOLD initiatives).

The natural history of COPD begins with complex biochemical and cellular events in the small airways and surrounding alveoli. Early in the course, damage to the structure leads to a loss of elastic recoil (Saetta, Ghezzo, et al 1985; Saetta, Shiner, et al 1985; Petty et al 1987). The lungs begin to increase in size, and the FVC increases (Petty et al 1987). This results in early physiologic alterations that can be readily identified by simple spirometry (Burrows et al 1987). By the time clinical signs are present, COPD is often in a moderateto-advanced stage (Mannino et al 2000).

Pathologic evidence of emphysema can be derived from CT studies or from resectional material, such as when solitary nodules are removed (Cosio et al 1978, 1986). The most practical way to diagnose and to access the functional progress of COPD is by spirometry. The initial smokinginduced injury to the human lungs appears to be in the small conducting air passages and surrounding alveoli. When alveoli become damaged or lost, the elastic supporting structure of the lung is reduced (Figures 1 and 2). This results in both a loss of elastic recoil and in increased airways 


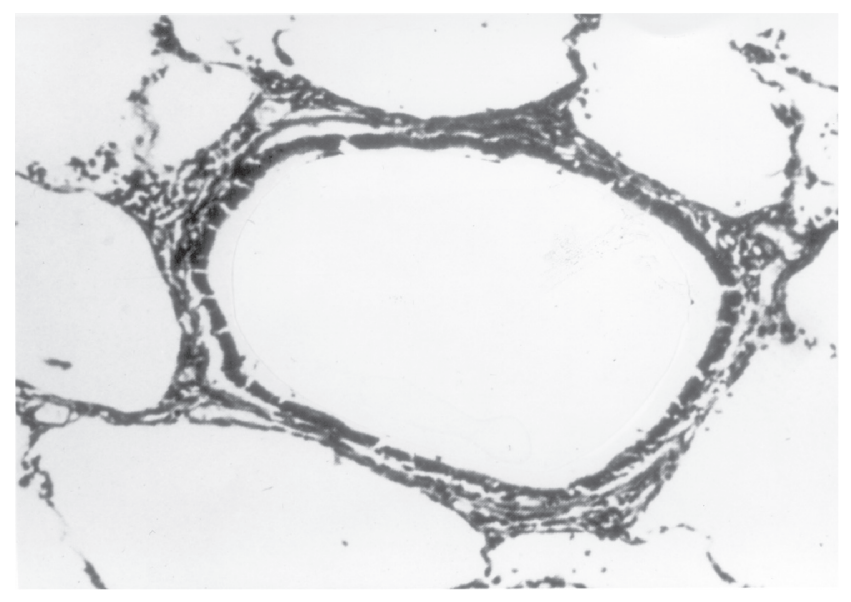

Figure I Small respiratory bronchiole with surrounding alveolar attachments. These alveolar attachments serve to tether small airways. Source: Petty T. 2002 COPD in perspective. Chest, I2I Suppl: I 16S-120S. Reproduced with permission from The American College of Chest Physicians.

resistance since airways are no longer tethered by the radial traction forces of the surrounding alveolar attachments. Mural inflammation of small airways and airways remodeling also reduce the airway lumen.

Thus, the interrelated causes of airflow obstruction in COPD patients include a combination of airways inflammation and remodeling, bronchospasm, mucous hypersecretion, and loss of elastic recoil. There is a complex interrelationship among these phenomena, which results in the progressive reduction in expiratory airflow as judged by the $\mathrm{FEV}_{1}$.

It deserves emphasis that early stages of emphysema are characterized by both hyperinflation and an increased FVC (Burrows et al 1987; Petty et al 1987). This is the reason why

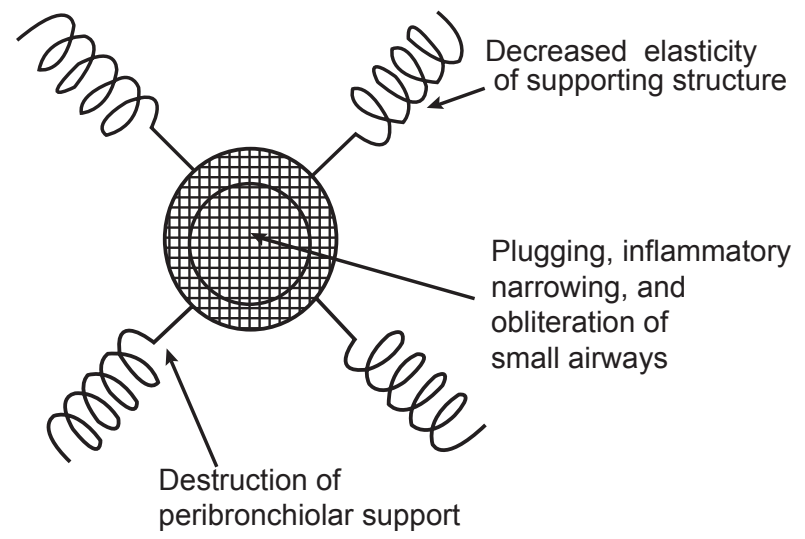

Figure 2 A drawing describing the mechanisms of airflow obstruction due to the losss of elastic recoil and airway narrowing. Source: Petty T. 2002. COPD in perspective. Chest, 121 Suppl:II6S-120S. Reproduced with permission from The American College of Chest Physicians. the $\mathrm{FEV}_{1} / \mathrm{FVC}$ ratio is such a sensitive test for early stages of airflow obstruction. An $\mathrm{FEV}_{1} / \mathrm{FVC}$ of $<70 \%$ heralds the onset of rapid declines in $\mathrm{FEV}_{1}$ over the course of a 10 -year period (Burrows et al 1987). The time course of these changes in alveoli and small airways is illustrated in Figure 3. Thirty or more years of progressive loss in airflow may take place before the threshold to dyspnea on exertion occurs, which is usually at $<1.5 \mathrm{~L} / \mathrm{s}$ and may be as low as $1.0 \mathrm{~L} / \mathrm{s}$ in smaller persons.

\section{Treatment of COPD: past, present, and future}

Over 47 years ago, when the author graduated from medical school, the only therapies for COPD were antibiotics for pneumonia, potassium iodide used as a mucus thinner, and combination products containing ephedrine, a small amount of theophylline, and a minor amount of sedative to deal with the side effects of ephedrine. Inhaled isoproterenol began to be used in the early 1960s. In that era, oxygen was considered contraindicated, and exercise was prohibited for fear of straining the right heart. Corticosteroids were almost never used, even in cases of exacerbations of COPD. One paper in the early 1960s by Noehren, offered new hope that at least some treatments might be beneficial in emphysema. Both medical and surgical approaches to therapy were described (Noehren 1962).

\section{Management of acute respiratory failure}

Beginning in the early 1960s, patients with COPD began to be saved with the use of mechanical ventilators for the management of acute respiratory failure (Petty 1971). The development of systematic therapy for nonhospitalized patients can be traced to the 8th Aspen Emphysema Conference, which was held in June 1965 (Petty 1967). This was the only Aspen Emphysema Conference devoted entirely to treatment. The Denver Group presented their first observations on ambulatory oxygen at the conference. The many topics discussed by clinicians and scientists at the conference included principles of pulmonary rehabilitation, the treatment of cor pulmonale, home care for chronic pulmonary insufficiency, and surgical treatments for emphysema. The subsequent 22nd, 26th, and 42nd Aspen Lung Conferences also had COPD as their theme.

\section{Long-term oxygen therapy (LTOT)}

In the first Denver studies of ambulatory oxygen, patients with chronic stable hypoxemia experienced remarkable 


\section{Natural History of COPD}

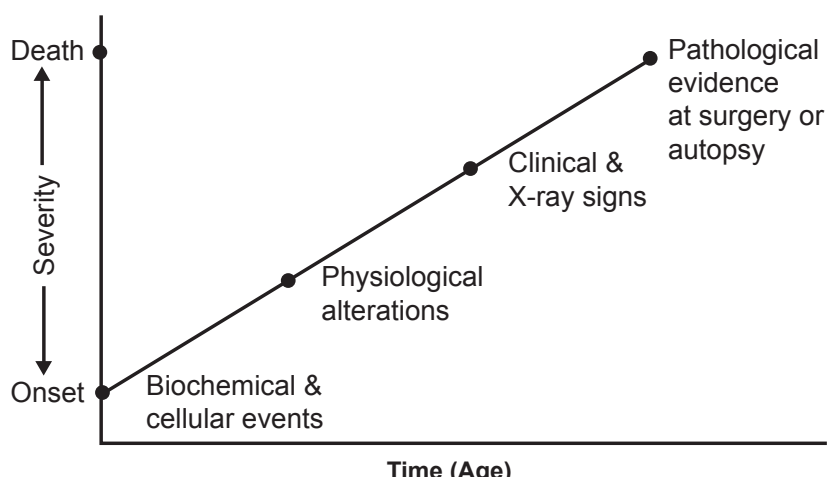

Figure 3 The natural history of COPD. Source: Petty T. 2002. COPD in perspective. Chest, 121 Suppl: I I6S-120S. Reproduced with permission from The American College of Chest Physicians.

reductions in pulmonary hypertension and erythrocytosis, along with a great increase in exercise tolerance (Levine et al 1967). This and several other early pilot studies resulted in the design of the Nocturnal Oxygen Therapy Trial (Nocturnal Oxygen Therapy Trial Group 1980). The Medical Research Council Clinic Trial compared $15 \mathrm{~h}$ of oxygen with air breathing (The Medical Research Council Working Party 1981). Together, these two studies established the scientific basis of long-term oxygen therapy, which is the only treatment that has been proven to alter the course of disease and prognosis of patients with advanced COPD (Petty 1990).

\section{Pulmonary rehabilitation}

Pulmonary rehabilitation evolved from that earlier era (Petty et al 1969; Petty 1993). The systematic use of drugs to restore pulmonary function, including bronchoactive drugs (ie, bronchodilators and corticosteroids) began to gain popularity in the 1990s. An emphasis on the importance of smoking cessation became a feature of treatment in the 1990s.

\section{Surgery}

The technique of Lung Volume Reduction Surgery (LVRS), originally introduced by Brantigan and Mueller (1957) and was resurrected by Cooper and others in the 1990s (Cooper et al 1996). A randomized controlled clinical trial completed in 2003 showed no reduction in mortality but an improved quality of life in a subset of surgical patients (National Emphysema Treatment Trial Group 2003). A subset of patients with primarily upper lobe disease and poor exercise tolerance following pulmonary rehabilitation did have a small but significant survival benefit (National Emphysema Treatment Trial Group 2003).

Lung transplantation is established for a small number of patients, due to the lack of organ availability (Studer et al 2004). Long-term survival for lung transplantation is limited by a high index of organ rejection and bronchiolitis obliterans (Studer et al 2004).

\section{Corticosteroids and bronchodilators}

Five studies (Paggiaro et al 1998; Pauwels et al 1999; Vestbo et al 1999; Burge et al 2000; The Lung Health Study Research Group 2000), which were conducted in the 1990s on therapy with inhaled corticosteroids have resulted in interesting and somewhat conflicting conclusions. Although a small subset of patients has a slight step-up in $\mathrm{FEV}_{1}$ following the administration of inhaled corticosteroids, the rate of decline in $\mathrm{FEV}_{1}$ was not retarded in any of the studies completed thus far. However, symptoms of cough, expectoration, and exacerbations of chronic bronchitis were significantly reduced in patients in the treatment groups compared with those in the placebo group. Symptomatic benefits need to be weighed against the possibility of systemic side effects (eg, reduced bone density) if inhaled corticosteroids are to be used in the long term (The Lung Health Study Research Group 2000).

Improved survival in COPD using a combination of fluticasone propionate and salmeterol has been suggested in case controlled studies (Soriano et al 2002; Sin and Man 2003). Prospective randomized controlled studies are currently in progress to attempt to confirm these findings.

\section{COPD as a systemic disease}

It has been learned that patients with only mild stages of COPD may have significant cardiovascular physiologic impairments. These individuals cannot achieve maximum oxygen uptake or a maximum heart rate. Their exercise performance is limited and is likely due to physical deconditioning, even in patients with only mild degrees of airflow obstruction and without hypoxemia (Carter et al 1993). We must now recognize COPD as a systemic disease and start to understand the metabolic and musculoskeletal implications of this generalized process (Schols et al 1996, 1998). COPD has been recognized as a risk factor for cardiovascular morbidity and mortality (Sin and Man 2005). Thus corticosteroids may (or may not) have a beneficial role on the underlying systemic nature of COPD. Obviously this is an area that requires intense factor investigation. 
The pathogenesis of pulmonary hypertension in COPD and its treatment also remain a huge challenge (Higgenbottom 2005). We need to learn much more about the molecular genetics of COPD (Sanford et al 1997). Why do only $15 \%-20 \%$ of smokers develop airflow obstruction (Sanford et al 1997)?

\section{The Lung Health Study}

Following a preliminary meeting organized by the author in 1982 during his presidency of the American College of Chest Physicians and attended by many experts who were both for or against studies of early identification, the Lung Health Study was planned and implemented by the Lung Division of the National Heart, Lung, and Blood Institute (NHLBI). In all 10 centers, 5887 volunteers were enrolled who were heavy smokers between the ages of 35 and 60, and who had any degree of airflow obstruction identified at baseline screening (Anthonisen et al 1994). Subjects were randomized to receive special care or usual care in a 2:1 ratio. Half of the subjects randomized to special care received ipratropium bromide and the other half an identical placebo inhaler. The initial report of outcome

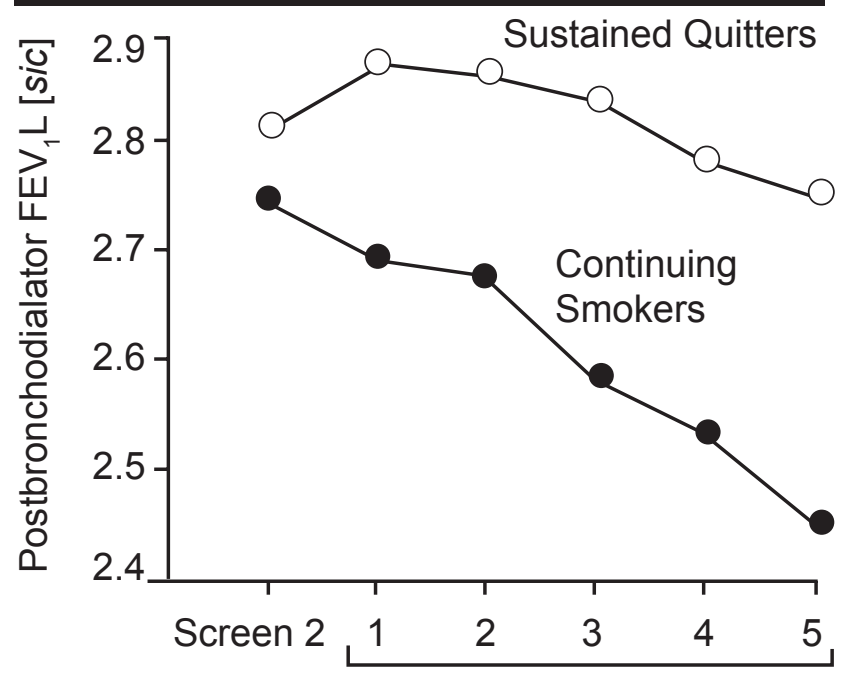

Follow-up, y

Figure 4 Mean post-bronchodilator forced expiratory volume at I second $\left(\mathrm{FEV}_{1}\right)$ for participants in the smoking intervention and placebo group who were sustained quitters $(\mathrm{O})$ and continuing smokers $(\boldsymbol{O})$. The two curves diverge sharply after baseline. Source: Anthonisen NR, Connett JE, Kiley JP. I994. Effects of smoking intervention and the use of an inhaled anticholinergic bronchodilator on the rate of decline of FEVI. The Lung Health Study. JAMA, 272:1497-505. Copyright (c) 2004. American Medical Association. All rights reserved. Reproduced with permission from AMA. showed that $22 \%$ of patients who received special care stopped smoking as part of the study, compared with 5\% in the usual care group. Patients who succeeded in stopping had a small improvement in $\mathrm{FEV}_{1}$ initially, followed by a slow decline up to five years of follow-up (Figure 4). Ipratropium did not improve baseline lung function, but did increase airflow on each day that it was tested over the course of the study.

The most common cause of death was lung cancer (57), compared with 37 cardiac deaths and 55 deaths from all other cancers $(\mathrm{N}=149)$. At a 14.5-year follow-up, the most common cause of death remained lung cancer (33\%), with cardiovascular deaths the second most common cause of death $(22 \%)$. Coronary artery disease was also a common cause of death but the death records had an overlap with the designation of cardiovascular deaths. Seven point 8 percent (7.8\%) died of nonmalignant respiratory disease. Two point three percent (2.3\%) died of unknown causes. This powerful study showed conclusively that stopping smoking in middle age (Anthonisen et al 2005) was associated with a much better survival than in patients who continued to smoke. This study and others form the scientific basis for early identification of COPD and related disorders, the most common of which is lung cancer.

\section{The NLHEP and GOLD initiatives}

Following a preliminary planning meeting in 1993 and a comprehensive workshop on COPD sponsored by the Lung Division of the NHLBI, the need for a new national health initiative for the early diagnosis, treatment, and research in COPD was launched in a major publication (Petty and Weinmann 1997) and later on gained full support in CHEST (Petty 1998). Soon thereafter, the National Lung Health Education Program (NLHEP) was founded by the author, who was its first chairman. Initial NIH support was supplemented by unrestricted grants from the pharmaceutical industry. All major societies with a stake in COPD sent representatives to the biennial board of directors meeting held at the times of the American College of Chest Physicians and ATS. Numerous publications and recommendations followed. The most notable was the consensus's statement of the NLHEP, which recommended the spirometric testing of all smokers aged 45 or older and anyone with chronic cough, dyspnea on exertion, mucus hypersecretion, or wheeze (Ferguson et al 2000). This helped promote the development of accurate and inexpensive office spirometers for widespread use. In 2004, the NLHEP's administrative functions were 
transferred to the American Association for Respiratory Care (AARC), and a new Chairman, Professor Dennis Doherty of the University of Kentucky, succeed the author, who remains Chairman Emeritus and is still actively involved (Petty and Doherty 2004).

In 2001, the Global Initiative of Obstructive Lung Disease (GOLD) was launched by the WHO and NHLBI (Pauwels et al 2001; Global Initiative for Chronic Obstructive Lung Disease 2004). International in scope, GOLD offered a new classification of the severity of COPD, which is now accepted by most societies and organizations. Together, the NLHEP and GOLD will continue to raise awareness of the importance of COPD and promote early identification and intervention.

\section{Recent biologic studies and therapeutic targets}

The pathogenesis of COPD is complex and involves multiple mechanisms. The bottom line of these processes is inflammatory damage of the conducting airways and vascular damage of the alveolar surface of the lung, which constitutes the air-blood interface. Capillary damage leads to loss of both alveolar walls and reduced elastic recoil. Inflammatory obstruction of small airways contributes to airflow obstruction; the loss of alveolar walls and airflow obstruction (as Laënnec first described) are part and parcel of the pathogenesis.

The inflammatory process of COPD is initiated by inhalation of noxious gases in cigarette smoke and in the environment. All airways, including the central airways, become inflamed, which results in mucous gland hyperplasia and hypersecretion. Macrophages and CD8 cells are the prime cellular mediators, which include leukotriene $\mathrm{B}_{4}$, interleukin-8, and tumor necrosis factor (TNF) (Barnes 2000). Thus, the inflammatory processes of COPD are markedly different from those of asthma. Inflammation in asthma consists of more corticosteroid-responsive cells and mediators, such as mast cell-activated eosinophils, T-helper type 2 lymphocytes (CD4 phenotype), and a number of cytokines whose production is decreased by use of corticosteroids. This may explain, at least in part, why patients with COPD are not nearly as responsive as patients with asthma to both inhaled and systemic steroids.

The protease-antiprotease imbalance is certainly true in the alpha-1-antitrypsin deficiency state. Matrix metalloproteinases, collagenases, and other tissue-degrading enzymes are released from macrophages and neutrophils.
An oxidant-antioxidant imbalance also exists in small airways and at the air-blood interface. How this can be dealt with therapeutically remains a challenge. Potentially, many other mechanisms (including processes that trigger mucus hypersecretion or cause dysfunction) and inhibition of growth factors (such as vascular endothelial growth factor at a reduced level) result in premature apoptosis of capillaries and the alveolar walls they nourish (Kasahara 2001). Phosphodiester 4 inhibitors are a new class of drugs that may oppose or otherwise modify the basic inflammatory processes of the small and large airways. Specific cytokine antagonists (eg, 1, 2, and 3) on TNF2 inhibitors are the subject of current investigations (Barnes 2000). Systemic clinical approaches to patients with COPD and cardiovascular disease are emerging (Soriano et al 2002; Rennard 2005; Sin and Man 2005). All of this new knowledge about the pathogenesis of emphysema and related airway inflammation promises new therapeutic targets for the future.

\section{Summary}

The evolution of our understanding of emphysema and chronic bronchitis covers nearly four centuries. Anatomists, clinical scientists from many disciplines, and clinicians have contributed to the knowledge that an attack on alveoli and both large and small airways contribute to the emergence of chronic and ultimately irreversible airflow limitation, due to loss of elastic recoil and increase in airflow resistance through the complex conducting system of the lungs.

Dyspnea is due primarily to abnormal lung and thoracic mechanics and the increased work of breathing. Cough and mucus hypersecretion are due to inflammation, mucous gland hyperplasia, and goblet cell hyperplasia. One or more host factors are involved in many patients, and family clustering may go beyond alpha-one-antitrypsin deficiency. COPD must be considered a systemic disease.

Treatment requires an elimination of smoking and other irritants in the environment. Such measures forestall or prevent the premature loss of ventilatory function and loss of blood gas homeostasis.

Treatment of symptomatic disease, beyond smoking cessation requires the use of bronchodilators and probably corticosteroids. Pulmonary rehabilitation and oxygen improve the quality and length of life in selected patients. Lung volume reduction surgery improves lung mechanics and reduces dyspnea by improving elastic recoil, which affects both airflow and perfusion, thus ameliorating gas exchange 
abnormalities in selected patients. Lung transplantation helps a few patients.

The future requires early identification and intervention in the basic disease processes. Spirometry must emerge as the fundamental way to diagnose and monitor responses to therapy. It must be employed by all who care for patients with COPD. New therapies must reduce both alveolar damage and inflammation of the airways. The future for COPD science and improved prevention and patient care appears bright.

\section{References}

Anthonisen NR, Connett JE, Kiley JP, et al. 1994. Effects of smoking intervention and the use of an inhaled anticholinergic bronchodilator on the rate of decline of $\mathrm{FEV}_{1}$ : The Lung Health Study. JAMA, 272:1497-505.

Anthonisen NR, Skeans MA, Wise RA, et al. 2005. The effect of a smoking cessation intervention on 14.5-year mortality. A randomized clinical trial. Ann Inter Med, 142:233-9.

Badham C. 1814. An essay on bronchitis: with a supplement containing remarks on simple pulmonary abscess. 2nd ed. London: J Callow.

Baillie M. 1799. The morbid anatomy of some of the past important parts of the human body divided into 10 fasciculi. London: W Blum R and Co.

Barach AL, Bickerman HA. 1956. Pulmonary emphysema. Baltimore: Williams and Wilkins.

Barnes PJ. 1998. New therapies for chronic obstructive pulmonary disease. Thorax, 53:137-47.

Barnes PJ. 2000. Chronic obstructive pulmonary disease. N Engl J Med, 343:269-80.

Bishop PJ. 1959. Samuel Johnson's lung. Tubercle, 40:478-81.

Bonet T. 1679. Sepulchretum sive anatonia pructica ex Cadaveribus Morbo denatis, proponens Histoa's Observations omnium pené humani corporis affectuum, ipsarcomoue Causas recorditas revelans. Geneva.

Bovard D. 1912. Internal medicine. Philadelphia: Lippincott.

Brantigan OC, Mueller E. 1957. Surgical treatment of pulmonary emphysema. Am Surg, 23:784-804.

Briscoe WA, Nash ES. 1965. The slow space in chronic obstructive pulmonary disease. Ann N Y Acad Sci, 121:706-22.

Buhl R, Farmer SG. 2005. Future directions in the pharmacologic therapy of chronic obstructive pulmonary disease. Proc Ann Thorac Soc, 2: 83-93.

Burge PS, Calverley PM, Jones PW, et al. 2000. Randomized, double blind, placebo controlled study of fluticasone propionate in patients with moderate to severe chronic obstructive pulmonary disease: the ISOLDE trial. BMJ, 320:1297-303.

Burrows B, Earle RH. 1969. Course and prognosis of chronic obstructive lung disease. A prospective study of 200 patients. $N$ Engl J Med, 280:397-404.

Burrows B, Fletcher CM, Heard BE, et al. 1966. The emphysematous and bronchial types of chronic airways obstruction. A clinicopathological study of patients in London and Chicago. Lancet, 1:830-5.

Burrows B, Knudson RJ, Camilli AE, et al. 1987. The "horse-racing effect" and predicting decline in the forced expiratory volume in one second from screening spirometry. Am Rev Respir Dis, 135: $788-93$.

Carter R, Nicotra B, Blevins W, et al. 1993. Altered exercise gas exchange and cardiac function in patients with mild chronic obstructive pulmonary disease. Chest, 103:745-50.

Choe KH, Taraseviciene-Stewart L, et al. 2003. Methylprednisolone causes matrix metalloproteinase-dependent emphysema in adult rats. Am J Respir Crit Care Med, 167:1516-21.
Christie RV. 1944. Emphysema of the lungs (part II). BMJ, 1-145.

Ciba Guest Symposium. 1959. Terminology, definitions, and classification of chronic pulmonary emphysema and related conditions. Thorax, 14:286-99.

Committee on Diagnostic Standards for Nontuberculous Respiratory Diseases, American Thoracic Society. 1962. Definitions and classification of chronic bronchitis, asthma, and pulmonary emphysema. Am Rev Respir Dis, 85:762-9.

Cooper JD, Patterson GA, Sundaresan RS, et al. 1996. Results of 150 consecutive bilateral lung volume reduction procedures in patients with severe emphysema. J Thorac Cardiovasc Surg, 112:1319-29.

Cosio MG, Ghezzo H, Hogg JE, et al. 1978. The relationship between structural changes in small airways and pulmonary-function tests. N Engl J Med, 298:1277-81.

Cosio MG, Shiner RJ, Saetter M, et al. 1986. Alveolar fenestrate in smokers. Relationship with light microscopic and functional abnormalities. Am Rev Respir Care, 133:126-31.

Donald KW. 1971. Identification of asthma. Chairman's opening remarks. Ciba Foundation Study Group. Volume 38. p 104.

Eiseman B, Petty T, Silen W. 1959. Experimental emphysema. Am Rev Resp Dis, 80:147-52.

Fletcher G, Peto R, Tinker C, et al. 1976. The natural history of chronic bronchitis and emphysema. New York: Oxford Pr.

Ferguson GT, Enright PL, Buist SA, et al. 2000. Office spirometry for lung health assessment in adults. A consensus statement from the National Lung Health Education Program. Chest, 117:1146-61.

Gaensler EA. 1950. Air velocity index; a numerical expression of the functionally effective portion of ventilation. Am Rev Tuberc, 62:17-28.

Gaensler EA. 1951. Analysis of the ventilatory defect by timed capacity measurements. Am Rev Tuberc, 64:256-78.

Global Initiative for Chronic Obstructive Lung Disease. 2004. Global Strategy for Diagnosis, Management of Chronic Obstructive Pulmonary Disease. NHLBI Workshop Report 2003. Accessed 7 Oct 2005. URL: http://www.goldcopd.com.

Gough J. 1952. Discussions on the diagnosis of pulmonary emphysema. The pathologic diagnosis of emphysema. Proc R Soc Med, 45:576-7.

Gross P, Babyak MA, Tolker E, et al. 1964. Enzymatically produced pulmonary emphysema. A preliminary report. J Occup Med, 6:481-4.

Heard BE. 1969. Pathology of chronic bronchitis and emphysema. Baltimore: Williams and Wilkins.

Higgenbottom T. 2005. Pulmonary hypertension and chronic obstructive pulmonary disease: a case for treatment. Proc Am Thorac Soc, 2:12-19.

Hinshaw HC, Garland LH. 1956. Disease of the chest. Philadelphia: WB Saunders.

Hogg JC, Macklem PT, Thurlbeck WM. 1968. Site and nature of airway obstruction in chronic obstructive lung disease. $N$ Engl J Med, 278:1355-60.

Hutchinson J. 1846. On the capacity of the lungs, and on the respiratory functions, with a view of establishing a precise and easy method of detecting disease by the spirometer. Medico-Chirurgical Transactions (London), 29:137-61.

Kasahara Y, Tuder RM, Cool CD, et al. 2001. Endothelial cell death and decreased expression of vascular endothelial growth factor and vascular endothelial growth factor receptor 2 in emphysema. Am J Respir Crit Care Med, 163:737-44.

Laënnec RTH. 1821. A treatise on the diseases of the chest (English translation from the French). Preface and notes by Forbes J. London: T and $\mathrm{G}$ Underwood.

Laënnec RTH. 1837. A treatise on mediate auscultation and on diseases of the lungs and heart (English translation of 4th ed). Herbert T (ed). London: Bailliere.

Laurel CB, Erickson S. 1963. The electrophoretic alpha-1-antitrypsin pattern of globulin in alpha-1 antitrypsin deficiency. Scand J Clin Lab Invest, 15:132-40.

Levine BE, Bigelow DB, Hamstra RD, et al. 1967. The role of long-term continuous oxygen administration in patients with chronic airway obstruction with hypoxemia. Ann Intern Med, 66:639-50. 
Mannino DM, Gagnon RC, Petty TL, et al. 2000. Obstructive lung disease and low lung function in adults in the United States: data from the National Health and Nutrition Examination Survey, 1988-1994. Arch Intern Med, 160:1683-9.

Mitchell RS (ed). 1959. Symposium on emphysema and chronic bronchiolitis. Am Rev Respir Dis, 80(Suppl):1-213.

Mitchell RS, Ryan SF, Petty TL, et al. 1966. The significance of morphologic chronic hyperplastic bronchitis. Am Rev Resp Dis, 93:720-9.

Mitchell RS, Silvers GW, Dart GA, et al. 1968. Clinical and morphologic correlations in chronic airway obstruction. Am Rev Resp Dis, 97:54-62.

Mitchell RS, Stanford RE, Johnson JM, et al. 1976. The morphologic features of the bronchi, bronchioles, and alveoli in chronic airway obstruction. A clinicopathologic study. Am Rev Resp Dis, 114:137-45.

Morgagni GB. 1769. The seats and causes of disease. Investigated by anatomy; in five books, containing a great variety of dissections, with remarks. Translated by Alexander B, Miller A, Caldwell T. London: Johnson and Payne.

National Emphysema Treatment Trial Group. 2003. Randomized Trial Comparing Lung Volume Reduction Surgery with Medical Therapy for Severe Emphysema. N Engl J Med, 348:2059-73.

[NHLBI] National Heart, Lung, and Blood Institute Data Fact Sheet. 2003. Chronic obstructive pulmonary disease (COPD). Bethesda, Maryland US Dept Public Health and Human Services, National Institute of Health, National Heart, Lung, and Blood Institute; NIH publication nr 03-5229.

Nocturnal Oxygen Therapy Trial Group. 1980. Continuous or nocturnal oxygen therapy in hypoxemic chronic obstructive lung disease: a clinical trial. Ann Intern Med, 93:391-8.

Noehren TH. 1962. Pulmonary emphysema, improved outlook in the management of patients. JAMA, 182:889.

Norris GW, Landis HRM. 1918. Diseases of the chest and the principles of physical diagnosis. Philadelphia: WB Saunders.

Orie NGM, Sluiter JH (eds). 1960. The host factor in bronchitis. In: Bronchitis proceedings of the international symposium on bronchitis. Groningen: Assen Royal Vangorcum.

Osler W. 1916. The principles and practices of medicine: designed for the use of practitioners and students of medicine. 8th ed. New York Appleton.

Oswald NC, Harold JT, Martin WJ. 1953. Clinical pattern of chronic bronchitis. Lancet, 265:639-43.

Paggiaro PL, Dahle R, Bakran I, et al. 1998. Multicentre randomized placebo-controlled trial of inhaled fluticasone propionate in patients with chronic obstructive pulmonary disease: International COPD Study Group. Lancet, 351:773-80.

Pauwels RA, Buist AS, Calverley PM, et al. 2001. Global strategy for the diagnosis, management, and prevention of chronic obstructive pulmonary disease. NHLBI/WHO Global Initiative for Obstructive Lung Disease (GOLD) Workshop Summary. Am J Respir Crit Care Med, 163:1256-76.

Pauwels RA, Lofdahl CG, Laitinen LA, et al. 1999. Long-term treatment with inhaled budesonide in persons with mild chronic obstructive pulmonary disease who continue smoking: European Respiratory Society Study on chronic obstructive pulmonary disease. $N$ Engl $J$ Med, 340:1948-53.

Peto R, Speizer FE, Cochrane AL, et al. 1983. The relevance in adults of airflow obstruction, but not of mucus hypersecretion to mortality from chronic lung disease. Am Rev Respir Dis, 128:491-500.

Petty TL (ed). 1967. Management of chronic obstructive lung disease; conclusions of the Eighth Aspen Emphysema Conference. US Public health Service publication $\mathrm{nr}$ 1457. Washington: US Government Printing Office.

Petty TL. 1971. Chronic airway obstruction (Chapter 7). Petty TL (ed). Intensive and rehabilitative respiratory care. Philadelphia: Lea and Febiger.

Petty TL. 1990. Home oxygen: a revolution in the care of advanced COPD. Med Clin North Am, 74:715-29.
Petty TL. 1993. Pulmonary rehabilitation in chronic respiratory insufficiency: pulmonary rehabilitation in perspective; historical roots, present status, and future projections. Thorax, 48:855-62.

Petty TL. 1998. The National Lung Health Education Program (NLHEP). Strategies in preserving lung health and prevention of COPD and associated diseases. Chest, 113(Suppl):123S-163S.

Petty TL, Doherty DE. 2004. The National Lung Health Education Program: roots, mission, future directions. Resp Care, 49:678-83.

Petty TL, Miercort R, Ryan S, et al. 1965. The functional and bronchographic evaluation of postmortem human lungs. Am Rev Respir Dis, 92:450-8.

Petty TL, Nett LM, Finigan MM, et al. 1969. A comprehensive care program for chronic airway obstruction. Methods and preliminary evaluating of symptomatic and functional improvement. Ann Inter Med, 70:1109-20.

Petty TL, Ryan SF, Mitchell RS. 1967. Cigarette smoking and the lungs: relation to postmortem evidence of emphysema, chronic bronchitis, and black lung pigmentation. Arch Environ Health, 14:172-7.

Petty TL, Silvers GW, Stanford RE, et al. 1980. Small airway pathology is related to increased closing capacity and abnormal slope of phase III in excised human lungs. Am Rev Respir Dis, 121:449-56.

Petty TL, Silvers GW, Stanford RE. 1984. Small airway disease is associated with elastic recoil changes in excised human lungs. Am Rev Respir Dis, 130:42-5.

Petty TL, Silvers GW, Stanford RE. 1987. Mild emphysema is associated with reduced elastic recoil and increased lung size, but not with airflow obstruction. Am Rev Respir Dis, 136:867-71.

Petty TL, Weinmann GG. 1997. Building a national strategy for the prevention and management of and research in chronic obstructive pulmonary disease. JAMA, 277:246-53.

Reid L. 1960. Measurement of the bronchial mucous gland layer. A diagnostic yardstick in chronic bronchitis. Thorax, 15:132-41.

Reid L. 1967. The Pathology of emphysema. Philadelphia: JB Lippincott.

Rennard ST. 2005. Clinical approach to patients with chronic obstructive pulmonary disease and cardiovascular disease. Proc Ann Thorac Soc, 2:94-100.

Ryan SF, Vincent TN, Mitchell RS, et al. 1965. Ductectasia, an asymptomatic pulmonary change related to age. Med Thorac, 22:181-7.

Saetta M. 2001. Cellular and structural bases of chronic obstructive pulmonary disease. Am J Respir Crit Care Med, 163:1304-9.

Saetta M, Ghezzo H, Kim WD, et al. 1985. Loss of alveolar attachments in smokers. A morphometric correlate of lung function impairment. Am Rev Respir Dis, 132:894-900.

Saetta M, Shiner RJ, Angus GE, et al. 1985. Destruction index: a measurement of lung parenchymal destruction in smokers. Am Rev Respir Dis, 131:764-9.

Sanford AJ, Weir TD, Pare PD. 1997. Genetic risk factors for chronic obstructive pulmonary disease. Eur Respir J, 10:1380-91.

Scadding JG. 1959. Principles of definition in medicine with special reference to chronic bronchitis and emphysema. Lancet, 14:323-5.

Schols AM, Buurman WA, Staal van den Brekel AJ, et al. 1996. Evidence for a relation between metabolic derangements and increased levels of inflammatory mediators in a subgroup of patients with chronic obstructive pulmonary disease. Thorax, 51:819-24.

Schols AM, Slangen J, Volovics L, et al. 1998. Weight loss is a reversible factor in the prognosis of chronic obstructive pulmonary disease. Am J Respir Crit Care Med, 157:1791-7.

Silvers GW, Maisel JC, Petty TL, et al. 1974. Flow limitation during forced expiration in excised human lungs. J Appl Physiol, 36:737-44.

Silvers GW, Petty TL, Stanford RE. 1980. Elastic recoil changes in early emphysema. Thorax, 35:490-5.

Sin DD, Man SF. 2003. Inhaled corticosteroids and survival in chronic obstructive pulmonary disease: does the dose matter? Eur Respir J, 21:260-6.

Sin DD, Man SF. 2005. Chronic obstructive pulmonary disease as a risk factor in cardiovascular morbidity and mortality. Proc Am Thorac Soc, $2: 8-11$. 
Snider GL, Sherter CB. 1977. A one-year study of the evolution of elastase-induced emphysema in hamsters. J Appl Physiol, 43:721-9.

Soriano JB, Vestbo J, Pride NB, et al. 2002. Survival in COPD patients after regular use of fluticasone propionate and salmeterol in general practice. Eur Respir J, 20:819-25.

Stuart-Harris CH, Pownall M, Scothorne CM, et al. 1953. The factor of infection in chronic bronchitis. Q J Med, 22:121-32.

Studer SM, Levy RD, McNeil K, et al. 2004. Lung transplant outcomes: a review of survival, graft function, physiology, health-related quality of life and cost-effectiveness. Eur Respir J, 24:674-85.

The Lung Health Study Research Group. 2000. Effect of inhaled triamcinolone on the decline in pulmonary function in chronic obstructive lung disease. N Engl J Med, 343:1902-9.
The Medical Research Council Working Party. 1981. Long term domiciliary oxygen therapy in chronic hypoxic cor pulmonale complicating chronic bronchitis and emphysema. Lancet, 1:681-6.

Thurlbeck WM. 1976. Chronic airflow obstruction in lung disease. Philadelphia: WB Saunders.

Tiffeneau R, Pinelli AF. 1947. Air circulant et air captif dans l'exploration de la function ventilatrice pulmonaire. Paris Med, 133:624-8.

Vestbo J, Sorensen T, Lange P, et al. 1999. Long-term effect of inhaled budesonide in mild and moderate chronic obstructive pulmonary disease: a randomized controlled trial. Lancet, 353:1819-23.

Voelkel N, Taraseviciene-Stewart L. 2005. Emphysema - an autoimmune vascular disease? Proc Am Thorac Soc, 2:23-5. 